\title{
TRABALHO FUNDANTE E SUBSTÂNCIA DO SER SOCIAL SEGUNDO O ÚLTIMO LUKÁCS - OBSERVAÇÕES PRELIMINARES
}

\author{
Paulo Henrique Furtado de Araujo ${ }^{1}$
}

\begin{abstract}
Resumo:
O artigo, tem por objetivo demonstrar que Lukács, em sua Para uma Ontologia do Ser Social, situa a categoria trabalho (universal/geral) como fundante do Ser Social, categoria acionadora do processo de afastamento da barreira natural que associa-se ao processo de humanização do ser humano. A humanização do ser humano se revela como a substância específica do ser social. Substância que é continuidade na mudança, mas que também se modifica de acordo com cada formação social específica em que se apresenta e manifesta fenomenicamente. Decorre que a compreensão de substância oferecida por Lukács é totalmente distinta da apreensão idealista-religiosa predominante em amplos setores da tradição filosófica ocidental. Para Lukács, a possibilidade de se identificar a permanência, permite que se capture a coisa enquanto essência. Ainda assim, trata-se de uma essência em permanente devir e que se instaura a partir da protoforma do agir humano - o trabalho geral/universal. Por fim, o artigo expõe o tratamento dado por Lukács ao conceito de liberdade e como esse conceito de liberdade se associa ao de substância do ser social.
\end{abstract}

Palavras-Chave: Ontologia do Ser Social; Trabalho Fundante; Substância; Lukács; Marx.

\section{FUNDAMENTAL LABOUR AND SUBSTANCE OF THE SOCIAL BEING ACCORDING TO THE LAST BOOK OF LUKÁCS - PRELIMINARY REMARKS}

\begin{abstract}
:
The article aims to demonstrate that Lukács, in his Towards an Ontology of Social Being, places the category labour (universal/general) as the foundation of Social Being, a category that triggers the process of distancing from the natural barrier that is associated with the process of humanization of the human being. The humanization of the human being reveals itself as the specific substance of the social being. Substance that is continuity in change, but which also changes according to each specific social formation in which it appears and manifests itself phenomenally. It follows that the understanding of substance offered by Lukács is totally different from the idealist-religious apprehension prevalent in broad sectors of the Western philosophical tradition. For Lukács, the possibility of identifying permanence allows one to capture the thing as essence. Even so, it is an essence in permanent becoming and which is established from the protoform of human action - the general/universal work. Finally, the article exposes the treatment given by Lukács to the concept of freedom and how this concept of freedom is associated with that of the substance of the social being.
\end{abstract}

Keywords: Ontology of Social Being; Founding Labor; Substance; Lukács; Marx.

\section{Introdução}

O livro Para uma Ontologia do Ser Social de György Lukács constitui-se em um marco incontornável para todos os que postulam retomar o pensamento de Marx em sua radicalidade e livre de todo entulho teórico sob o qual foi soterrado ao longo do século

1 Professor da Faculdade de Economia da UFF, do PPGE-UFF, Coordenador do GEPOC-UFF e membro do NIEP-MARX-UFF. E-mail: phfaraujo@id.uff.br. http://orcid.org/0000-0003-1454-4888 
XX. Lukács sustenta que Marx instaura uma ontologia materialista do ser social e que seu pensamento, teoria e práxis, devem ser interpretados a partir dessa consideração. De partida, destacamos que a compreensão da categoria ontologia por Lukács afasta-se da concepção idealista-religiosa predominante no âmbito da filosofia. Para o autor, o ser social, em seu devir, manifesta uma substância que é permanência na mudança, mas que se modifica nesse processo de mudança sem que perca sua característica distintiva. Não se trata de uma substância imutável que apenas se revela ao longo da história humana. Para Lukács, a possibilidade de se identificar a permanência, permite que se capture a coisa enquanto essência. Ainda assim, trata-se de uma essência em permanente devir e que se instaura a partir da protoforma do agir humano - o trabalho geral/universal.

Por esse motivo, iniciamos o presente artigo com a apresentação da categoria trabalho enquanto categoria fundante do ser social e protoforma do agir humano para, na sequência, tratar das categorias de valor e substância - destacando que, nesse caso, valor diz respeito ao agir útil ou não para a realização do fim ideado pelo produtor, portanto, algo distinto do valor constitutivo da mercadoria que tem por substância o trabalho humano abstrato. Por fim, apresentamos como Lukács trata o conceito de liberdade e como ele se associa ao de substância do ser social.

\section{O Trabalho enquanto Categoria Fundante do Ser Social}

Inicialmente, para que não haja dúvidas, esclarecemos que trabalho, para Marx e Lukács, nada mais é do que a atividade humana que atende as carências básicas para a sobrevivência da nossa espécie. Ambos partem da constatação de que o ser humano é um ser carente, pois necessita de coisas que lhes são exteriores para sua sobrevivência: alimento, vestuário, habitação etc. O trabalho é um evento entre ser humano e natureza que tem por télos a satisfação dessas carências através do agir humano. No trabalho o indivíduo "medeia, regula e controla o seu metabolismo com a natureza. Ele se confronta com a matéria natural como uma potência natural” (MARX, 2017, p. 255). A realização da potência de ser forma útil (e atender as carências humanas) presente nessa matéria natural exige o movimento e desgaste do próprio corpo físico do produtor. Ao atuar sobre a natureza que lhe é exterior e modificá-la, de acordo com uma prévia ideia do que pretendia obter, o produtor modifica a si próprio, modifica a sua própria natureza. "Ele desenvolve potências que nela [sua própria natureza] jazem latentes e submete o jogo de suas forças a seu próprio domínio" (Idem). Esse é um trabalho especificamente humano,

\begin{tabular}{|l|l|l|l|l|}
\hline Qevista Qialectus & Ano 10 & n. 23 & Maio - Agosto 2021 & p. 365 - 394 \\
\hline
\end{tabular}


totalmente diferente das formas instintivas, das protoformas do trabalho presentes no ser orgânico. O distintivo é o pôr do fim (pôr teleológico) que antecede o agir, ou seja, trabalho especificamente humano envolve a realização da finalidade pretendida pelo produtor.

Patenteia-se que o tratamento dado à categoria ${ }^{2}$ trabalho, nesse momento, é de tomá-la como trabalho universal/geral, portanto, abstraindo as particularidades constitutivas de cada tipo de trabalho executado no interior de modos de produção específicos e determinados - uma abstração razoável ou real ${ }^{3}$. Um tipo de abstração que captura características universais do trabalho que se realiza em todo e qualquer modo de produção e, ao mesmo tempo, por ser uma abstração, incapaz de per se determinar a especificidade desses trabalhos. Determinar a especificidade exige considerar as mediações constitutivas de cada modo de produção - sobredeterminar a categoria - e assim reconstituir a categoria em sua manifestação fenomênicas.

Esclarecido o grau de abstração com que tomamos a categoria trabalho, sustentamos que Lukács, em sua Para uma Ontologia do Ser Social, opera no mesmo grau de abstração ao tratar da referida categoria. $\mathrm{O}$ autor magiar demonstra que o ser social pressupõe o ser orgânico e o ser inorgânico e somente através de um salto ontológico em relação ao ser orgânico ele (o ser social) pode surgir. Por sua vez, o ser orgânico, pressupõe o ser inorgânico e, de modo semelhante, só surge a partir de um salto ontológico em relação ao ser inorgânico. O autor oferece uma explicação para o salto ontológico ao dizer que o salto origina transformação na qualidade e na estrutura do ser a partir do qual o novo devém. O ser pressuposto traz em si as potencialidades, requisitos e determinações para que as formas superiores se realizem, não obstante, o devir das formas superiores não sobrevém como uma tendência linear, como uma continuidade ininterrupta. Lukács arremata dizendo que a "essência do salto é constituída por essa ruptura com a continuidade normal do desenvolvimento e não pelo nascimento, de forma súbita ou gradativa, no tempo, da nova forma de ser" (LUKÁCS, 2013, p. 46).

O trabalho é a categoria fundante do ser social por possibilitar o salto ontológico a partir do ser orgânico. O pôr teleológico, determinativo do trabalho especificamente humano, elabora uma nova objetividade, do que se pode depreender que

2 Lembrando que para Marx (2011, p. 59): “categorias expressam formas de ser, determinações de existência”. Assim sendo, Marx está sustentando que categorias são determinações ontológicas.

3 Sobre abstração razoável ou real, cf. Marx (2011), Chasin (2009) e Lukács (2011).

\begin{tabular}{|l|l|l|l|l|}
\hline Q & Ano 10 & n. 23 & Maio - Agosto 2021 & p. $365-394$ \\
\hline
\end{tabular}


a ruptura na reprodução normal do ser orgânico só é capaz de ocorrer a partir do trabalho e do seu pôr teleológico. Por ser fundante e por produzir uma nova objetividade, o trabalho vem a ser modelo de toda práxis social - em todas elas há pores teleológicos e o trabalho opera como protoforma dessas práxis, por evidente, sem mecanicismos ou determinismos. Lukács enfatiza que o pôr teleológico limita-se ao trabalho e, de modo amplo e verdadeiro, se apresenta na práxis humana em geral. Sem embargo, Lukács não alça o pôr teleológico ao cerne de uma cosmologia universal e, por esse motivo, pode resolver adequadamente a antinomia entre causalidade e teleologia; antinomia que na história da filosofia se apresenta como insolúvel. O autor explana que a causalidade "é um princípio do automovimento que repousa sobre si próprio e mantém esse caráter mesmo quando uma cadeia causal tenha o seu ponto de partida num ato de consciência" (LUKÁCS, 2013, p. 48). E assinala que a teleologia, em seu nível crucial,

\footnotetext{
é uma categoria posta: todo processo teleológico implica o pôr de um fim e, portanto, numa consciência que põe fins. Pôr, nesse contexto, não significa, portanto, um mero elevar-se-à-consciência, como acontece com outras categorias e especialmente com a causalidade; ao contrário, aqui, com o ato de pôr, a consciência dá início a um processo real, exatamente ao processo teleológico. Assim, o pôr tem, nesse caso, um caráter irrevogavelmente ontológico (LUKÁCS, 2013, p. 48).
}

Agora o autor pode sustentar, acompanhando Marx, que no ser social, teleologia só pode ocorrer na esfera do trabalho (ou da práxis humana). A práxis humana vital que é o trabalho é a única ocasião em que é possível evidenciar “ontologicamente um pôr teleológico como momento real da realidade material” (Idem, p. 49). A práxis do trabalho é impossível se não for antecedida pelo pôr teleológico, esse pôr determina o processo de trabalho, as etapas a serem executadas e as formas de execução.

Lukács alicerça que causalidade e teleologia surgem como reciprocamente excludentes quando tomadas abstratamente. Não obstante, esclarece que a separação do trabalho entre o pensar e o produzir (nóesis e poíesis) feita por Aristóteles e o fracionamento desse pensar (nóesis) em pôr do fim e investigação dos meios, realizado por Hartmann, possibilitam o desvelar da inseparável conexão entre causalidade e teleologia. No trabalho especificamente humano, o pôr do fim previamente pensado (idealidade) transforma a realidade natural ao introduzir uma materialidade que é qualitativamente nova em relação à própria natureza. Essa objetificação do novo exige uma reorganização das propriedades, forças, legalidades e causalidades existentes na 
natureza em acoplamentos e junções inteiramente novos em relação aos pré-existentes na própria natureza. Reorganizar as legalidades e causalidades dadas na natureza exige do produtor a correta apreensão do funcionamento do mundo existente. Em outras palavras, a investigação dos meios para a efetivação do pôr do fim exige o deciframento ou a apreensão mais adequada possível dos processos constitutivos do âmbito a ser transformado e de suas causalidades dadas. Nesse proceder transparece, por um lado, que há um conjunto de causalidades e legalidades que governam o mundo existente e que são independentes da consciência do produtor. Por outro lado, o produtor pode capturar conexões e funções existentes e reorganizá-las de modo a efetivar o seu pôr teleológico. Aqui a legalidade e causalidade dadas na própria natureza devém postas. $\mathrm{O}$ ato do trabalho enreda causalidade e legalidade ao pôr de finalidades e esse último exige a correta apreensão das causalidades e legalidades. A causalidade dada na natureza ganha um papel inteiramente novo na práxis do trabalho, sem que tenha ocorrido uma modificação em sua própria constituição enquanto coisa processual. O produtor reorganiza as legalidades e causalidades em combinações inteiramente novas, obtendo novas funções e novos modos de operar. Como o caráter ontológico das leis da natureza não se altera, ocorre que as legalidades e causalidades naturais dadas devém postas. Lukács arremata dizendo que a peculiaridade de serem postas "é a mediação da sua subordinação ao pôr teleológico determinante, mediante o qual, ao mesmo tempo que se realiza um entrelaçamento posto de causalidade e teleologia, tem-se um objeto, um processo etc. unitariamente homogêneo" (LUKÁCS, 2013, p. 55).

O resultado desse percurso que articula natureza e trabalho (meio e fim) é a constituição de uma coisa homogênea em si mesma que é o processo de trabalho e o seu resultado final, o produto do trabalho. A referida homogeneização deve ser concretizada dialeticamente considerando que o pôr do fim, momento distintivo do trabalho, nasce como necessidade social e precisa atender a esta necessidade. Essa duplicidade gera uma disparidade de raiz entre trabalho (fim) e meio (natureza) A homogeneização do pôr teleológico encobre uma importante questão, indicando que a preponderância do fim sobre os meios não é algo muito simples: a efetivação ou não do pôr de finalidade depende da adequada investigação dos meios e da captura das causalidades dadas e sua transformação em causalidade posta. A compreensão inadequada das legalidades e causalidades da natureza para a execução do pôr do fim, impede a efetivação desse pôr e ele permanece como uma ideia que não se realizou. Há aqui - na investigação dos meios

\begin{tabular}{|l|l|l|l|l|}
\hline Q & Ano 10 & n. 23 & Maio - Agosto 2021 & p. 365 - 394 \\
\hline
\end{tabular}


- o fundamento ontológico da conexão entre o trabalho e o saber científico (e o seu desenvolvimento posterior).

A reorganização das causalidades dadas em causalidades postas e a utilização das legalidades naturais para a execução de um fim previamente ideado, tem por resultado, como afirmamos acima, algo que é inteiramente novo em relação à natureza pré-existente. Evidenciando que já nas formas mais primitivas do pôr teleológico se produz, necessariamente, o novo, o trabalho produz o salto ontológico do ser orgânico para o ser social exatamente por produzir o novo permanentemente; o ser social é um “ente teleologicamente produzido" (LUKÁCS, 2013, p. 61). O ser social é o novo em comparação ao ser orgânico, ainda que este seja seu fundamento ineliminável, segue desse devir que já se pode identificar nas formas primeiras do trabalho a tendência ao afastamento das barreiras naturais. Se trabalho produz o novo, este novo exige a ampliação permanente do conhecimento adequado das causalidades e legalidades naturais, ou ainda, a redução do peso e importância da causalidade dada sobre a reprodução do indivíduo e do gênero humano. No ser inorgânico e no ser orgânico ocorre um permanente devir do mesmo, "um contínuo ser-outro" (Idem), somente o acaso pode produzir algo novo; no ser social a produção do novo está inscrita na própria constituição do ser.

Com o trabalho especificamente humano, a consciência deixa de ser, em sentido ontológico, um mero epifenômeno e adquire centralidade ao permitir (e impelir) que o produtor efetive modificações (transformadoras, reformadoras etc.) na natureza. Algo distinto verifica-se na consciência nos animais mais desenvolvidos, ainda que sua existência seja algo indisputável, não pode ir além de servir à manutenção e reprodução filogenética e ontogenética. Aqui a consciência se apresenta como um estágio parcial secundário do andamento da reprodução biológica e essa reprodução está sujeita às leis próprias da biologia - e isso também vale tanto para a reprodução filogenética quanto ontogenética. No caso do gênero humano, a centralidade da consciência só pode ser demonstrada na práxis humana. Já sabemos que o trabalho constitui a protoforma do agir humano e agora podemos concluir que o trabalho especificamente humano, tomado enquanto categoria universal/geral, é a causa primeira do processo de humanização do ser humano.

A consciência humana em sua determinação do existir, aciona dois atos que são heterogêneos, mas intrinsecamente correlacionados: o espelhamento e o pôr de

\begin{tabular}{|l|l|l|l|l|}
\hline Qovista Dialectus & Ano 10 & n. 23 & Maio - Agosto 2021 & p. 365 - 394 \\
\hline
\end{tabular}


cadeias causais. O espelhamento só vem a ser com a separação efetiva entre sujeito e objeto, dizendo de outro modo, para que o produtor espelhe a realidade natural em sua consciência é preciso que existam objetos independentes do sujeito que espelha. Ao realizar esse ato de consciência, o sujeito (produtor), com graus variados de acuidade, se apropria intelectualmente do real dado. A separação sujeito e objeto é uma exigência do trabalho especificamente humano e o fundamento para o existir humano em sua especificidade puramente social. No espelhamento constitui-se uma emulação da realidade reproduzida pela consciência que devém específica da consciência. Essa "realidade" não é exatamente uma realidade, mas uma conformação de objetividade e, adverte Lukács (2013, p. 66), devido a esse fato - e tratando ontologicamente a questão - não é possível que essa nova objetividade (reprodução ideal da realidade) seja semelhante ou idêntica à realidade existente que é reproduzida na consciência. Segue, revela Lukács, que o ser social se divide em dois estágios heterogêneos e opostos: o ser existente objetivamente e o espelhamento desse ser pela consciência que procura capturar suas causalidades e legalidades do real existente.

O espelhamento ao se voltar para o ser-em-si do objeto natural, em sua totalidade real incomensurável e que é independente da consciência, e buscar apreendêlo através de sua reprodução ideal, pode incorrer em erros. Os sistemas de mediação que o ser social criou ao longo de sua história, complexificam o processo de espelhamento, todavia, a possibilidade do erro permanece associada a distância entre a consciência que objetiva o real pensado e o ser-em-si da realidade concreta. Lukács (2013, p. 67), nesse ponto, adverte que as reproduções ideais do real são ocasionadas pelos pores teleológicos - "em termos genéticos, pela reprodução social da vida, na sua origem pelo trabalho" por esse motivo a reprodução ideal do ser-em-si real nunca será uma cópia fotográfica perfeita desse real. Para o autor magiar, na orientação teleológica do espelhamento está a matriz da sua fertilidade em descobrir novidades; a objetivação, propiciada pelo espelhamento, atua em direção contrária. O desenlace dessa tensão é o produto da interação dessas tendências opostas - o que sempre ocorre com os complexos do ser social.

Na continuidade de sua exposição, Lukács ressalta que o espelhamento, tomado ontologicamente, é exigência crucial para o arranjo das cadeias causais e ainda que não seja ser, e sim forma de objetividade, não pode ser entendido, como faz Hartmann, enquanto "existência espectral da possibilidade" (LUKÁCS, 2013, p. 68). O 
pôr teleológico, também tomado ontologicamente, tem no seu nível essencial a potencialidade (dynamis) aristotélica ${ }^{4}$ - ele pode ou não se efetivar enquanto realidade em-si. No processo de trabalho universal/geral, o caráter alternativo de qualquer pôr aí realizado se manifesta na passagem do espelhamento (forma de não-ser) ao ser produtivo que põe nexos causais; aqui se apresenta a própria potencialidade (dynamis) "que pode ser considerada como caráter alternativo de qualquer pôr no processo de trabalho" (LUKÁCS, 2013, p. 70). A seleção das matérias-primas e dos instrumentos a serem utilizados no processo de trabalho são atos de consciência que se associam ao espelhamento do ser-em-si através da experiência e da observação. Nessa seleção há duas escolhas que se interrelacionam de maneira heterogênea: (a) é adequado ou não escolher determinada matéria-prima para um determinado fim? (b) O télos almejado é adequado ou não? Essas duas escolhas só podem vir-a-ser se têm por princípio um sistema de espelhamento do ser-em-si existente que é "um sistema de atos não existentes em-si" e que "funciona dinamicamente e é dinamicamente elaborado" (LUKÁCS, 2013, p. 71). O salto ontológico do ser natural (orgânico e inorgânico) para o ser social só pode ocorrer quando há a consolidação dos efeitos do espelhamento (que é um não-existente) em uma práxis constituída de maneira a produzir alternativa.

Para enfatizar, dada a importância da questão, somente as alternativas que se apresentam ao produtor de valores de uso no ato do trabalho (universal/geral) podem transformar a potência em ente. Esse é o limite superior da possibilidade de a potência vir a ser ente; o limite inferior é o que especifica quando e como um reflexo da realidade orientado pela consciência para uma realização pode devir possibilidade (LUKÁCS, 2013, p. 75). O atendimento de necessidades, e as representações ideais sobre essas necessidades, determinam a conformação do projeto a ser executado, os pontos de vista e as tentativas de espelhar adequadamente as relações causais da realidade existente. Toda racionalidade acionada para a práxis do trabalho depende da necessidade concreta que o produto singular deve atender. Segue que a racionalidade nunca pode ser absoluta; tratase da racionalidade concreta de uma conexão "se...então". A alternativa só se torna possível porque no interior da estrutura social predominam essas conexões necessárias e a alternativa, para se apresentar no interior do complexo concreto, pressupõe a ocorrência sucessiva de passos singulares (LUKÁCS, 2013, p. 76).

4 Lukács (2013, p. 69-70), citando Aristóteles, destaca que o que tem potência de ser também tem a potência de não ser. Dessa maneira, o dynamei ou a potencialidade é de ser e de não ser.

\begin{tabular}{|l|l|l|l|l|}
\hline Qonista & Ano 10 & n. 23 & Maio - Agosto 2021 & p. 365 - 394 \\
\hline
\end{tabular}


Oferecendo uma primeira abordagem do conceito de liberdade, Lukács lembra que alternativa e predeterminação são reciprocamente excludentes e alternativa é o fundamento ontológico da liberdade de decisão. Como alternativa, nesse nível de abstração da exposição de Lukács, é alternativa presente na práxis do trabalho, ela (alternativa) não pode se referir à realidade em geral. Trata-se de alternativa entre rotas cujo télos é, em última instância, produto do ser social no interior do qual o produtor age, decide e produz ${ }^{5}$. O escopo decisório é balizado pelo complexo concreto de ser no interior do qual ele (produtor) existe, esse complexo oferece possibilidades determinadas que o produtor pode tomar como objetos do seu pôr teleológico. Eis que é o ser social complexo e concreto que estipula "o pôr das cadeias causais no interior do pôr teleológico" (LUKÁCS, 2013, p. 76). Em suma, do processo social real surgem o pôr teleológico e a revelação e utilização dos meios e a determinação do terreno das perguntas e respostas das alternativas que podem via a ser efetivadas. No ato da alternativa há o momento da escolha dentre alternativas; a consciência do produtor é o lugar no qual essa escolha se efetiva, sendo essa função ontológica da consciência humana o que retira o caráter epifenomênico que a consciência possui nos animais - a consciência animal é subordinada ao instinto e à biologia - e concede posição de fenômeno principal à consciência.

Lukács arrisca apresentar, de forma breve, a gênese ontológica da liberdade a partir do ato da alternativa no interior do processo de trabalho (universal/geral) produtor de valores de uso. Já sabemos, com Lukács, que a alternativa é a categoria que permite a efetivação da potência (dynamei), agora precisamos apresentar o seu cerne ontológico primordial. Lukács sugere que o atributo cognitivo é a condição preponderante. Ampara essa compreensão sinalizando que a busca da satisfação da necessidade leva o humano a interpor, entre a necessidade e sua satisfação, o pôr do fim (o trabalho) e destacando que é essa a diferença com o proceder dos animais mais desenvolvidos - neles a satisfação é atendida pelos instintos determinados biologicamente. A simples presença do trabalho especificamente humano focaliza o comportamento consciente-cognitivo do produtor como momento crucial do atendimento das necessidades e demarca a diferença entre o comportamento instintivo dos animais superiores e a mediação, entre necessidade e atendimento, que é realizada pelo trabalho. Ou ainda, o trabalho especificamente humano

5 “O sujeito só pode tomar como objeto de seu pôr de fim, de sua alternativa, as possibilidades determinadas a partir e por meio desse complexo de ser que existe independentemente dele” (LUKÁCS, 2013, p. 76).

\begin{tabular}{|l|l|l|l|l|}
\hline Qovista Dialeatus & Ano 10 & n. 23 & Maio - Agosto 2021 & p. 365 - 394 \\
\hline
\end{tabular}


se apresenta como uma conquista do procedimento em que a consciência devém dominante sobre o puro instinto. Todo produtor busca o êxito de sua empreitada, para isso o seu pôr do fim e suas escolhas dos meios são determinados pela apreensão mais adequada possível do ser-em-si objetivo. Além disso, quanto aos fins e meios, o produtor tem que proceder do modo mais adequado possível ao seu ser-em-si. O que exige o domínio da consciência sobre o instinto e do conhecimento sobre o puramente emocional, pois instinto e emoções podem estorvar a intelecção objetiva do ser-em-si existente.

O espelhamento apropriado do ser-em-si é pré-condição para que o trabalho aconteça e é o que é capaz de efetivar as causalidades naturais “cujo caráter heterogêneo e indiferente com respeito ao pôr do fim pode conduzir à sua transformação em causalidade posta, a serviço do pôr teleológico" (LUKÁCS, 2013, p. 79). Nosso autor prossegue e explica que, em último caso, as alternativas concretas do trabalho acarretam tanto a definição do fim quanto a execução dos passos para a obtenção desse fim, ou seja, alternativas concretas produzem uma escolha entre certo e errado - aqui temos "sua [da alternativa] essência ontológica" (Idem). Essa essência, continua Lukács, pode ser resumida como a capacidade de transmudar a potência (dynamis) em efetuação concretafactual. Aqui o caráter cognitivo fundamental das alternativas do trabalho se revela como uma característica permanente, sendo esse caráter cognitivo primário “o ontológico serpropriamente-assim do trabalho" (Idem). E, arremata Lukács, o ser-propriamente-assim ontológico do trabalho pode ser ontologicamente identificado como completamente autônomo "das formas de consciência nas quais ele se realizou originalmente e talvez até por muito tempo depois" (Idem).

O que Lukács (Idem) delineia com essa exposição é que a "consequência ontológica necessária do ser-propriamente-assim objetivo do trabalho" é a transformação do produtor, do sujeito da ação; a conclusão sugerida pelo autor é que a partir da protoforma do agir humano (trabalho) temos o início do vir-a-ser humano do ser humano. O domínio da consciência sobre o instinto e emoções, que se inicia no trabalho especificamente humano já em suas formas primitivas, exige sua renovação permanente, conformando uma continuidade que se faz presente em cada trabalho singular enquanto uma nova alternativa. Com a efetivação do télos do trabalho, a consciência (enquanto intelecção correta das causalidades dadas) reforça seu domínio sobre o instinto e as emoções. Ocorre que o aspecto biológico-instintivo do ser humano (sua pura animalidade) se transforma na medida em que as cadeias causais dadas do ser-em-si 
humano são adequadamente conhecidas e, no processo de trabalho, devém cadeias causais postas para a obtenção de um fim. O produtor, para a execução adequada do trabalho, de acordo com a prévia ideação, necessita controlar seus movimentos físicos e seu intelecto em sentido oposto ao proceder puramente instintivo-emocional. Nesse processo, a potência (dynamis) do que há de especificamente humano no ser humano se efetiva e temos o devir humano do ser humano a partir da protoforma do agir humano (trabalho universal/geral). A experiência acumulada pelo gênero humano a partir dos trabalhos singulares executados e continuamente repetidos toma o rumo de uma dinâmica dupla que exclui e perpetua os movimentos usuais da práxis do trabalho. Os movimentos são perpetuados enquanto reflexos condicionados, que se assemelham ao agir instintivo dos animais superiores por serem inconscientes (ainda que resultantes de atos conscientes que se conservam na práxis do trabalho), todavia, eles podem ser revogados, encontrando seu fim, e sendo substituídos por outros reflexos condicionados - desde que a dinâmica da interação do trabalho singular com o todo complexo societário assim o exija. Em suma, o reflexo condicionado traz consigo a marca que o originou - o pôr teleológico "que cria uma distância, determina os fins e os meios, controla e corrige a execução" (LUKÁCS, 2013, p. 81).

O distanciamento entre sujeito e objeto associado ao espelhamento é o que obriga o produtor a dominar conscientemente seus instintos e emoções. Esse domínio envolve comportamentos cruciais para o vir-a-ser humano do ser humano e alicerça os temas basilares de qualquer sistema ético-moral. O trabalho especificamente humano dá início ao longo processo de autodomínio do ser humano, pois esta é condição necessária para a efetivação do fim previamente ideado e efetivado na práxis do trabalho. $\mathrm{O}$ autodomínio, por evidente, exige o afastamento das barreiras naturais e a afirmação da determinação puramente social do ser humano. No âmbito da constituição do ser social, que se inicia com o salto ontológico do trabalho, temos que destacar o pôr teleológico que já não incide sobre a primeira natureza ou não se ocupa dos processos de mediação entre o produtor e a natureza a ser transformada para a produção de valores de uso; mas que tem por objetivo influenciar a consciência de outros seres humanos para realizarem, $\mathrm{em}$ última instância, pores teleológicos concretos que envolvem interação produtor e natureza para a produção de valores de uso. Esses são uma segunda forma de pôr teleológico ou pores teleológicos secundários e, enquanto o pôr teleológico primário visa 
mobilizar cadeias causais, o pôr teleológico secundário busca mobilizar outro pores teleológicos.

\section{Valor e Substância}

A produção do novo no sujeito é consequência inevitável do par categorial teleologia e causalidade posta. Retomando o fato de que o pôr teleológico e sua efetivação são o que instauram o humano singular em sua humanidade, constatamos que estamos diante de uma práxis para a qual o dever-ser é o momento determinante imediato. Qualquer movimento para a realização do pôr do fim é um dever-ser na medida em que tal movimento exige a averiguação do se e como ele (o movimento) efetiva o pôr do fim. Decorre que há uma inversão na determinação da causalidade no ser social em comparação ao ser orgânico; no ser orgânico há um desenvolvimento causal em que o passado determina o presente. No ser social o fim (presente na consciência do produtor) vem antes da realização. Com o intuito de melhor esclarecer esse ponto, vamos tomar o exemplo de Lukács: ocorre que uma modificação no meio ambiente provoca a adaptação/adequação dos seres vivos e essa adequação provém de uma necessidade causal - "as propriedades produzidas no organismo por seu passado reagem a tal transformação, conservando-se ou destruindo-se" (LUKÁCS, 2013, p. 98). Como já foi dito, no caso do ser social o fim, presente na consciência do produtor, antecede a sua realização. Dizendo de outro modo, cada ação adotada no processo de produção é orientada pelo futuro já presente na consciência do produtor. As causalidades dadas no ser natural são selecionadas, reorganizadas e acionadas com o objetivo da realização do fim já posto no início do processo do trabalho. Segue que no processo de trabalho as legalidades da natureza se realizam em causalidades não mais espontâneas, mas orientadas pelo pôr do fim do processo de trabalho especificamente humano. No processo de trabalho há a orientação teleológica da causalidade dada no ser natural e o pôr de um processo causal que envolve o aperfeiçoamento da seleção, orientação e organização dos processos causais dados e espontâneos. Lukács conclui, corretamente, que para o produtor "esse agir determinado a partir de um futuro definido é exatamente um agir conduzido pelo dever-ser do fim" (LUKÁCS, 2013, p. 98).

O espelhamento adequado das causalidades dadas e a passagem para causalidades postas, além da escolha dos procedimentos adequados para o efetivação do

\begin{tabular}{|l|l|l|l|l|}
\hline Q & Ano 10 & n. 23 & Maio - Agosto 2021 & p. 365 - 394 \\
\hline
\end{tabular}


fim, só podem vir-a-ser a partir do fim previamente ideado. O espelhamento correto da realidade é condição para que o dever-ser opere, ainda assim, a opção entre alternativas que se apresentam no processo de trabalho só podem ser avaliadas como certas ou erradas, falsas ou verdadeiras, a partir do fim que é a efetivação do pôr teleológico. Com isso torna-se patente que no par categorial dever-ser e espelhamento (teleologia e causalidade posta) o momento predominante é do dever-ser. Essa constatação nos impele a enfatizar a gênese do dever-ser a partir da essência teleológica do trabalho e a destacar que, entre o trabalho como modelo do agir humano e os agires mais complexos, vigora a relação de identidade da identidade e não identidade que explicitaremos em seguida. Antes, cabe reafirmar que o dever-ser ontologicamente determinado na práxis do trabalho determina o comportamento do sujeito no processo de trabalho e, ao mesmo tempo, determina seu comportamento consigo mesmo enquanto sujeito dessa práxis. Segue-se que o processo do trabalho ao constituir o télos, o objeto e os meios, ocasiona a essência do agir subjetivo, do que podemos concluir que a subjetividade assim constituída cumpre uma função auxiliar na realização da prévia ideação. O autodomínio humano, que tem início com o trabalho especificamente humano, é corolário imperioso do dever-ser mobilizado na práxis do trabalho. Esse autodomínio é organizado e guiado pela objetividade do processo, a objetividade do processo de trabalho, considerando sua essência, tem por arrimo a existência real-concreta do objeto e dos meios de trabalho. Temos que partir dessa objetividade reguladora para apreender adequadamente como o dever-ser, no trabalho, atua sobre o sujeito e sua consciência. O procedimento concreto que se verifica no trabalho é o decisivo para o próprio trabalho; o intercorrer endógeno ao sujeito que trabalha não necessariamente afeta o próprio processo de trabalho. Ainda que, como já dito, o dever-ser do trabalho, engendre o início do autocontrole humano sobre seus instintos e emoções e, portanto, seja o ponto inicial do desenvolvimento de qualidades humanas que serão decisivas para o surgimento de práxis mais desenvolvidas; tais modificações nos indivíduos não são direcionadas, inicialmente, para a totalidade da singularidade enquanto pertencente ao gênero humano - na verdade, essas modificações agem, de imediato, no próprio trabalho.

Observando, mais uma vez, os pores teleológicos secundários, não é difícil constatar que tanto a subjetividade do sujeito que põe a finalidade secundária quanto a subjetividade do humano que se quer influenciar, sofrem modificações - agora a autotransformação do sujeito é o objeto dos pores teleológicos (secundários) e estes pores

\begin{tabular}{|c|c|c|c|c|}
\hline Q Rovista Dialeatus & Ano 10 & n. 23 & Maio - Agosto 2021 & p. 365 - 394 \\
\hline
\end{tabular}


têm a marca do dever-ser. Estamos diante de pores com maior grau de complexidade e qualitativamente diferentes dos pores primários, mantendo em comum com esses últimos o fato de que são conexões de dever-ser nas quais o futuro determina o agir presente. $\mathrm{Ou}$ dizendo o mesmo de outro modo, nesses casos não é o passado que determina o presente, ao contrário, é o futuro previamente ideado, objetivado como atividade teleologicamente posta para sua autorrealização o que determina o presente, ou seja, determina as práxis que a essa teleologia corresponde.

O fundamento biológico da condição humana é ineliminável, o que leva Marx e Lukács a acentuarem a especificidade do ser social e das categorias puramente sociais que surgem com o novo ser. Ao mesmo tempo, esse fato revela o motivo principal da importância, para o dever-ser no trabalho, que o metabolismo sociedade-natureza adquire. Lukács nos diz que estamos diante da simultaneidade de identidade e não identidade: a relação sociedade-natureza é a base para a eclosão do dever-ser em geral de toda práxis voltada para a satisfação de necessidades humanas e, ao mesmo tempo, é o alicerce da formação desse dever-ser em geral, "da sua qualidade particular e de todas as barreiras de determinação do ser que são geridas e determinadas por esse dever-ser enquanto forma e expressão de relações da realidade" (LUKÁCS, 2013, p. 105).

O dever-ser e o valor se apresentam como categorias do ser social que são indivisíveis. Já vimos que o dever-ser é decisivo para a práxis do trabalho, todavia, essa função só pode ser realizada porque o télos do trabalho constitui-se em algo que tem valor para o produtor. Segue daqui que o valor devém existente ao assentar o dever-ser da práxis de trabalho como o princípio que tem que orientar essa práxis; tipificando que valor e dever-ser são condição de um único e sui generis complexo - o complexo do trabalho. Lukács ensina que o valor, além de atuar principalmente sobre o pôr teleológico, é o princípio de avaliação do que é objetivado pelo trabalho; já o dever-ser vigora precipuamente como regulador do processo de trabalho. Essa diferença entre eles não elimina a interconexão antes assinalada, ao contrário, a concretiza. De todo modo, tomando o valor como algo que se associa e marca o produto final do processo de trabalho, a pergunta que surge, segundo Lukács, é se o caráter distintivo do valor é objetivo ou subjetivo, ou ainda, se o valor é ligado à objetividade do valor de uso que é reconhecido como valor no ato de valoração do produtor ao trabalhar ou se o valor se manifesta como consequência de atos valorativos? 
A explicação desse ponto leva o autor magiar a recorrer à categoria valor de uso. $\mathrm{O}$ valor de uso, com algumas poucas exceções, é produto do trabalho especificamente humano e sua produção, ao longo da história do gênero humano, é um processo que envolve o avanço das forças produtivas do trabalho e a maior socialização do trabalho, do que decorre o afastamento das barreiras naturais. Os valores de uso "representam uma forma de objetividade social" (LUKÁCS, 2013, p. 107) e enquanto produto do metabolismo entre a sociedade humana e a natureza, e ao passo que é algo presente em toda e qualquer formação social e sistema econômico, não sofre modificação histórica; contudo, suas formas fenomênicas se alteram entre formações e sistemas econômicos e, inclusive, no interior de uma mesma formação. Em suma, valor de uso é objetivo. A sua objetividade, como propriedade das coisas, causa estranheza se consideramos que a natureza apenas apresenta o processo contínuo do vir-a-ser que, por sua vez, é determinado causalmente. Lukács resume a questão dizendo que "só referida a um pôr teleológico a utilidade pode determinar a espécie de ser de qualquer objeto, apenas nessa relação pertence [a utilidade] à essência desse último, enquanto existente, ser útil ou o seu contrário" (LUKÁCS, 2013, p. 108). Na sequência, Lukács advoga que para chegar a essa conclusão a respeito da utilidade (que só pode ser determinada se referida a um pôr teleológico) era necessário, para a filosofia, elucidar a função ontológica do trabalho e, além disso, revelar que o trabalho é fundante do ser social.

Retomando a questão do valor, Lukács (2013, p. 111) adverte que sua (do valor) gênese ontológica tem como ponto inicial o trabalho especificamente humano produtor de valores de uso. Nesse trabalho, a alternativa que se apresenta é entre o que pode ou não satisfazer necessidades humanas, sendo, portanto, uma alternativa entre o que é útil e o que é inútil; a alternativa envolve a questão da utilidade e se instaura como ingrediente dinâmico do ser social. A objetividade do valor, conforme tratamos acima, traz em si a realização, ou efetivação, do valor em questão e, nesse caso, demonstra a correção do pôr de finalidades que originou o trabalho. Há que destacar o traço ontológico do "se...então" presente na concreção do valor ${ }^{6}$. A disseminação de que uma objetivação do trabalho humano é valor (é útil) - somente quando pode atender da maneira mais adequada possível às necessidades humanas - articula a relação "se...então" no interior de uma "abstração orientada para a legalidade". Lukács arremata dizendo que por essa

6 Diz Lukács (2013, p. 111): “uma faca tem valor se corta bem”.

\begin{tabular}{|l|l|l|l|l|}
\hline Qovista Dialectus & Ano 10 & n. 23 & Maio - Agosto 2021 & p. 365 - 394 \\
\hline
\end{tabular}


razão "o valor que aparece no trabalho enquanto processo que reproduz valor de uso é sem nenhuma dúvida objetivo" (LUKÁCS, 2013, p. 111). E isso por dois motivos: por um lado, a objetivação do pôr teleológico pode ser mensurada e, por outro, o pôr do fim em questão, portador da relação "se...então" com a satisfação das carências humanas, do mesmo modo pode ter sua existência demonstrada e comprovada em sua objetividade e validez. Segue que não é adequado sustentar que o valor seja constituído por pores singulares que atribuem valor à coisa objetivada. Na verdade, "o valor que aparece no processo e que confere a este uma objetividade social é que decide sobre se alternativa no pôr teleológico e na sua realização é adequada a ele, isto é, se era correta, valiosa" (LUKÁCS, 2013, p. 112).

Quando consideramos um todo complexo mais desenvolvido no interior do qual predominam pores teleológicos secundários, percebemos que a questão do valor é muito mais intrincada, multívoca e polissêmica do que pudemos descrever para o caso do metabolismo sociedade e natureza. Tomando a tendência geral do complexo econômico de ampliar sua socialização, podemos vislumbrar a distância que o separa do simples trabalho produtor imediato de valores de uso que estávamos analisando acima. O complexo econômico mais desenvolvido, portanto, mais mediado, é produto de pores teleológicos singulares, das alternativas que a eles se apresentam e de suas efetivações. Os valores, que têm sua origem ontológica nesse trabalho simples produtor de valores de uso permanecem, enquanto objetividade, no complexo econômico mais mediado. Segue que as cadeias de causa e efeito, desencadeadas pelo pores teleológicos singulares, interagem de modo imediato e mediato resultando no devir social enquanto totalidade em processo. Se no trabalho simples, criador de valores de uso, as decisões tomadas pelo produtor se orientam pelo valor com convicção plena; ocorre que a totalidade complexa em processo, atingido certo padrão, já não pode mais ser imediatamente assimilada pelos produtores singulares que instauram os pores teleológicos e acionam as alternativas. Agora, objetivamente o valor já não determina os pores teleológicos com a certeza apropriada e, subjetivamente, o faz sem uma consciência satisfatória. Os produtores já não podem depreender adequadamente as legalidades das deliberações tomadas, todavia, o valor continua existindo objetivamente e, por ser objetivo, prescreve os pores teleológicos singulares que, necessariamente, são guiados pelos valores.

Um exemplo da manifestação dessa realidade no complexo econômico mais mediado é o princípio do governo do tempo ou da economia de tempo. Retomando Marx 
dos Grundrisse, Lukács lembra que "economia de tempo, a isto se reduz afinal toda economia” (MARX, 2011, p. 119) e, dessa maneira, o autor húngaro assinala uma lei transistórica do ser social - o que é uma outra forma de apresentar a tendência ao recuo das barreiras naturais que tratamos anteriormente ${ }^{7}$. Ocorre que as consequências de diversos fenômenos produzidos por incontáveis pores teleológicos se condensam nessa lei e retornam sobre os pores teleológicos singulares definindo-os de tal modo que cada produtor singular tem que se adequar a lei da economia do tempo ou perecer. Segue disso que a lei da economia de tempo também é uma relação de valor e apreender adequadamente essa característica é decisivo para a reconstituição da leitura de Lukács sobre o processo de humanização do ser humano e da determinação da substância específica do ser social.

Sabemos, com Lukács (2013, p. 114) pelo exposto anteriormente, que no trabalho simples, produtor de valores de uso, o produtor, por um lado, domina as causalidades e legalidades da natureza inorgânica e orgânica, buscando o atendimento de suas carências especificamente humanas e, por outro lado, dá início ao domínio sobre seus instintos, emoções e afetos - sendo esse o ponto de partida da gênese das faculdades especificamente humanas do ser humano. Agora, constatamos que a legalidade endógena do complexo econômico que constitui a economia de tempo, associa-se à divisão social do trabalho e a sua consequente complexificação e é a origem da tendência à pura sociabilidade do ser social. Dizendo o mesmo de outro modo: esse andamento rumo a economia de tempo, engendra a pura sociabilidade - sem levar em conta as maneiras de compreensão dos produtores que o acionam - e é manifestamente a rota que percorrem as categorias desde

\footnotetext{
seu ser-em-si originário até um ser-para-si sempre mais ricamente determinado e sempre mais efetivo. Ora, a encarnação adequada desse ser-para-si da socialidade desdobrada, que chegou a si mesma, é o próprio homem. (...), o homem na sua concreta práxis social, o homem que com suas ações e nas suas ações encarna e faz realidade o gênero humano (LUKÁCS, 2013, p. 114).
}

Lukács, recorrendo mais uma vez ao Marx dos Grundrisse, escora a ideia de que economia de tempo é a verdadeira economia e, portanto, essa poupança de tempo é sinônimo de desenvolvimento das forças produtivas. Marx arremata essa questão dizendo

Sobre a incompreensão dessa lei transistórica e a identificação da ontologia com metafísica, ver Postone (2014). Duayer e Araujo (2020a e 2020b) e Araujo (2020a).

\begin{tabular}{|l|l|l|l|l|}
\hline Q & Ano 10 & n. 23 & Maio - Agosto 2021 & p. 365 - 394 \\
\hline
\end{tabular}


que "poupança de tempo de trabalho é o equivalente ao aumento de tempo livre, i.e., tempo para o desenvolvimento pleno do indivíduo, desenvolvimento este que, como maior força produtiva, retroage sobre a força produtiva do trabalho" (MARX, 2011, p. 593). Torna-se inequívoca a associação que Marx realiza entre o desenvolvimento econômico e o desenvolvimento do ser humano. O produtor singular ao pôr finalidades e realizar escolhas dentre alternativas constitui um complexo dinâmico gerador de legalidades (como a economia de tempo) que está para além da vontade desse produtor singular e o constrange enquanto realidade social determinada e concreta. Esse complexo dinâmico, em sua processualidade, contraditória e dialética, faz e refaz "tanto as relações que tornam possível o desenvolvimento superior do ser humano como, no próprio ser humano, aquelas faculdades que transformam em realidade tais possibilidades" (LUKÁCS, 2011, p. 115) ${ }^{8}$. Concluímos que o ser humano, para Marx e Lukács, é o alfa e o ômega de todo esse processo, ele é a sua essência real.

Nesse ponto, Lukács transparece que está considerando a sociedade do capital como exemplo da manifestação do caráter objetivo do valor econômico ${ }^{9}$. Diferenciando valor econômico do valor presente na atividade simples de trabalho humano produtor de valores de uso, advoga que a objetividade do valor econômico, estribado no metabolismo ser humano e natureza (trabalho especificamente humano), apresenta um caráter objetivo que ultrapassa essa momento primordial. Isso ocorre, como vimos, a partir da tendência inerente ao processo de trabalho (mesmo o mais simples) de deslanchar a legalidade da economia de tempo, aumento da força produtiva e recuo das barreiras naturais, que produzem o processo de humanização do ser humano. $\mathrm{O}$ valor econômico, prossegue o autor, apresenta um incremento qualitativo em relação ao valor associado ao trabalho simples e produtor de valores de uso, constituindo um duplo movimento antinômico: por um lado, acentua-se a especificidade da utilidade do valor rumo à totalidade da vida humana, ou seja, no sentido do universal. Para Lukács a marca distintiva desse processo é o devir progressivamente abstrato da utilidade que tem por ápice o período em que "o valor de troca, sempre mediado, elevado à universalidade e em si mesmo contraditório, assume um papel de guia nos intercâmbios sociais dos homens" (LUKÁCS, 2013, p. 116).

\footnotetext{
8 A Boitempo optou por traduzir Menschen por homem, todavia, entendemos que o mais adequado seria traduzir como ser humano, por isso apresentamos a citação com essa alteração.

9 Ainda que o texto não seja claro o suficiente para afirmarmos que o que Lukács chama, nesse ponto, de valor econômico é o valor - categoria específica da sociedade do capital e momento predominante da contradição constitutiva da forma mercadoria - assim o interpretamos.
}

\begin{tabular}{|c|c|c|c|c|}
\hline Qevista Dialectus & Ano 10 & n. 23 & Maio - Agosto 2021 & p. $365-394$ \\
\hline
\end{tabular}


Como o valor de troca ${ }^{10}$ não pode eliminar seu pressuposto, o valor de uso, o que temos é uma nova categoria (valor de troca) que não nega abstratamente o valor de uso, mas, ao contrário, é produto dialético de especificações primordiais encontradas na sua própria gênese enquanto valor de troca. Por outro lado, prossegue Lukács, esse devir, que comandou e orientou a constituição do primeiro modo de produção puramente social - a sociedade do capital ${ }^{11}$ - é um processo contraditório pois se trata da constituição de uma sociabilidade desenvolvida a partir da produção e que é um sistema social encerrado em si mesmo, arrimado no econômico. Sabemos que para essa esfera da vida (econômica) a práxis real só vem a ser tendo por fundamento os pores teleológicos e as investigações dos meios para a efetivação desses pores - ambos imanentes à esfera do econômico e orientados por ela. Segue que o estabelecimento ontológico da esfera do econômico esclarece seu vínculo com outras esferas da práxis humana, sendo mantida a prioridade ontológica do econômico em relação a essas outras esferas.

Considerando uma esfera do ser social, no caso a econômica, a partir dessa figuração ontológica, passamos a ter condições para explicar a gênese do desenvolvimento de categorias mais complexas e mediadas, portanto, segundo Lukács, superiores, a partir de categorias mais simples ou fundantes. Lukács (2013, p. 117), com isso rejeita tanto a dedução ontológica das categorias e valores em que se parte do conceito geral abstratamente compreendido; quanto rejeita a ontologia materialista vulgar que sustenta que as categorias complexas ou superiores são produtos mecânicos das categorias simples ou fundantes. Essa especificação é muito importante para compreender e explicar de modo adequado a relação entre o valor econômico e os outros valores presentes em outras práxis sociais.

Já abordamos a diferença entre os pores teleológicos primário e secundário, agora, ao tratarmos do complexo econômico mais mediado e mais concreto, verificamos que esses pores sofrem alterações. Por evidente, quanto mais mediado for o ser social, maior a importância dos pores secundários, todavia, os pores primários passam por modificações que, ainda que não alterem sua essência primordial, produzem diferenças

10 O que Lukács chama, nesse trecho, de valor de troca é o valor. A pouca precisão no uso dessas categorias coloca dificuldades a mais para a interpretação do texto. Note que anteriormente o valor parecia ser tratado como valor econômico.

11 Lukács se refere aqui ao capitalismo e ao socialismo enquanto as criações desse processo. Naturalmente, no nosso entendimento, o chamado socialismo real nada mais era do que uma sociabilidade do capital em que as personificações do capital não eram as proprietárias de direito dos meios de produção e, ainda assim, toda vida humana tinha por eixo organizativo o valor em sua permanente auto expansão - ainda que configurasse um tipo de capital atrofiado. Sobre essa questão cf. ARAUJO, 2016 e 2108.

\begin{tabular}{|l|l|l|l|l|}
\hline Q Rovista Dialectus & Ano 10 & n. 23 & Maio - Agosto 2021 & p. 365 - 394 \\
\hline
\end{tabular}


que devem ser destacadas. No complexo econômico, o valor e os pores de valor, se tornam cada vez mais multifacetados tomando como ponto de partida os pores teleológicos primários. Avançando para outros complexos não econômicos, nos defrontamos com temas muito mais emaranhados e qualitativamente diferentes dos verificados na esfera do econômico. Tomando a esfera do direito como exemplo, Lukács adianta que nela se verifica a continuidade do ser social. Essa esfera (direito) surge como um tipo de práxis social e regulamentação da práxis social, adquire autonomia relativa ao longo da história da espécie humana sem, com isso, perder a característica distintiva de ser uma forma de medição que emergiu para cumprir a função de regular, de maneira mais eficiente, a reprodução do ser social. A autonomia relativa que possui em relação a esfera do econômico, além de sua estrutura díspar em comparação à estrutura do econômico, são componentes cruciais para que a esfera do direito cumpra sua função mediadora da forma mais eficaz possível. Dependência objetiva e heterogeneidade em relação à esfera do econômico tipificam a autonomia relativa da esfera do direito, segundo Lukács. A contradição dialética das duas esferas (economia e direito) determina a especificidade e a objetividade social do valor. Precisamos agora considerar, a partir do que já assinalamos acima, que os pores simples associados à produção de valores de uso já iniciam o desenvolvimento das faculdades especificamente humanas (em fases muito iniciais, apenas como dynamei) nos produtores singulares e nas suas relações sociais incipientes e garantem a gênese do gênero humano. Sendo evidente que as consequências da produção das faculdades especificamente humanas se põem para além da esfera do econômico ainda que não possam eliminar sua presença ou retirar-se do terreno do ser social ${ }^{12}$.

A interdependência entre problemas humanos e práxis real da vida social tem na contraditoriedade um importante momento. Lukács argumenta que as consequências mais extraordinárias do devir humano do ser humano já são engendradas por essas formas contraditórias e, por meio delas, considerando-as no sentido da pura sociabilidade, devém matrizes de impreteríveis confrontos de valor. A título de exemplo, Lukács (2013, p. 119) toma o desenvolvimento da esfera econômica, a partir do próprio salto ontológico do ser orgânico para o ser social, e lembra que ele não é teleologicamente posto enquanto tal,

12 Aqui é possível aduzir que a complexificação do ser social, o aumento das mediações sociais, a constituição de outros complexos não econômicos, assinala a perda de importância e da centralidade do trabalho produtor de valores de uso para a vida social. O recuo das barreiras naturais significa a redução do peso e importância do trabalho imediato para a reprodução do complexo de complexos que é o ser social.

\begin{tabular}{|l|l|l|l|l|}
\hline Qovista Dialectus & Ano 10 & n. 23 & Maio - Agosto 2021 & p. 365 - 394 \\
\hline
\end{tabular}


ainda que esteja arrimado nos pores teleológicos singulares de produtores singulares. Esses pores, vimos, acionam cadeias causais cujas manifestações fenomênicas (históricas e efetivas) facultam o surgimento de contradições entre o desenvolvimento objetivo da espécie humana, a partir do florescimento econômico, e seus resultados sobre o gênero humano.

Lukács acrescenta que se a escolha dentre alternativas em relação ao desenvolvimento econômico, e tendo por modelo o trabalho simples produtor de valores de uso, é inequívoca; quando se trata de posicionamento moral sobre os efeitos do econômico sobre a vida de cada singularidade humana, verifica-se um antagonismo de valores. A explicação para isso, prossegue Lukács (2013, p. 120), é que o decurso econômico e social acontece com uma unitariedade estabelecida de modo legal-causal e as respostas a esse decurso têm que ocasionar uma pronta unitariedade de valor. No trabalho, que em seu nível mais crucial é o próprio metabolismo entre sociedade humana e natureza, a unitariedade que opera na tomada de posição das alternativas econômicas e das não econômicas (ético-morais) é flagrante. Quando o desenvolvimento da sociabilidade, com o correspondente afastamento das barreiras naturais, faz com que a esfera econômica, em sua condição objetiva, venha a ser "segunda natureza" e, simultaneamente, quando concentra-se, principalmente no plano econômico, o teor da alternativa de cada singularidade; temos que a unitariedade em questão torna-se atual. De um modo geral, a contraditoriedade (que muitas vezes assume a forma de um antagonismo direto) entre a esfera do econômico e suas manifestações fenomênicas (humano-sociais) adquire o predomínio; em outras palavras, a legalidade do econômico ao fomentar o antagonismo direto entre a essência do processo econômico e as formas fenomênicas pelas quais ele se manifesta no mundo social-humano, faz desse antagonismo um dos alicerces ontológicos do próprio desenvolvimento social em sua totalidade.

Com o intuito de esclarecer o seu argumento, Lukács (2013, p. 121) nos fala que a superação do comunismo primitivo por comunidades cindidas entre possuidores e não possuidores ${ }^{13}$, promove as singularidades à condição de possuidora ou não possuidora e, com isso, as decisões vitais de cada singularidade constitutiva da universalidade, que é

13 Lukács, na verdade, fala da superação do comunismo primitivo pela sociedade de classes. Como, em nosso entendimento, sociedade de classes só pode surgir com a sociabilidade do valor, o adequado é falar, nesse nível de análise, de sociedade dividida entre possuidores e não possuidores. Para maiores explicações ver Araujo, 2016, 2018, 2020a e 2020 b.

\begin{tabular}{|l|l|l|l|l|}
\hline Q & Ano 10 & n. 23 & Maio - Agosto 2021 & p. 365 - 394 \\
\hline
\end{tabular}


a comunidade, passam a ser significativamente estipuladas por sua condição de possuidor ou não possuidor. Constitui-se um tipo de sociabilidade na qual a essência das decisões alternativas se coloca para além do simples metabolismo sociedade-natureza e com a presença imanente de formas fenomênicas conflituosas. Nesse caso, prossegue o autor, as alternativas estão orientadas para a seleção de valores que se confrontam reciprocamente; agora a práxis é estabelecida como uma luta entre valores concretos providos de validade factual.

$\mathrm{Na}$ tentativa de estabelecer a diferença entre valores e a realização de valores em suas consumações nas múltiplas configurações de mudança e de permanência na mudança, Lukács (2013, p. 121-122) indica, em linhas gerais, esse transcurso tomando como exemplo a “decisão socialmente correta ante uma alternativa importante" (Idem, p. 122). Para tanto, ele oferece o conceito de substância como ponto de partida de sua exposição. Ponderando que, no âmbito da filosofia e da ciência, as apreensões contemporâneas do ser solaparam o entendimento de que substância seja algo estático e imutável, sustenta que uma ontologia materialista do ser social deve reconhecer a substância desse ser como portadora de um caráter primordialmente dinâmico. Nesse enquadramento, o autor define que substância é algo que "na contínua mudança das coisas, mudando ela mesma, pode conservar-se em sua continuidade" (Idem). E acrescenta que essa autoconservação não significa que substâncias sejam eternas. Ao contrário, contanto que permaneçam dinamicamente ao longo o período de tempo do seu existir, substâncias podem nascer e morrer e, ainda assim, serão substâncias.

Em seguida, articulando o conceito de valor com o de substância, Lukács recupera a compreensão de que o trabalho (já em sua forma de simples produtor de valores de uso) é a protoforma da práxis humana e que os valores autênticos constituem uma condição imprescindível dessa práxis. Como visto acima, substância é o que no devir do ser social, em sua reprodução social, permanece enquanto continuidade ainda que se modificando; considerando que o ser social é um complexo de complexos que por sua vez são sínteses de pores teleológicos que só existem acionando tomadas de posição em que se aceita ou rejeita um valor, conclui-se que valores adquirem relevo ontológico no ser social por serem objetos dos pores teleológicos - eis aqui a realização dos valores. A matriz da geração ontológica do valor não pode ser tomada como sua realização, pois valores se originam da mudança incessante da conformação do ser social e os valores, que surgem dessa mudança incessante, manifestam-se justamente pelos pores

\begin{tabular}{|l|l|l|l|l|}
\hline Qevista Qialectus & Ano 10 & n. 23 & Maio - Agosto 2021 & p. 365 - 394 \\
\hline
\end{tabular}


teleológicos que realizam os valores. Sabemos que o ser humano, com mais ou menos consciência, no seu cotidiano, se defronta com (e toma posição em relação as) alternativas efetivas que são produzidas a partir do desenvolvimento da sociabilidade a que pertence esse indivíduo que decide - aqui o valor já está abarcado. Um valor pode vir a ser efetivo socialmente sem assumir uma forma consciente para o produtor singular, basta tomar como exemplo o domínio sobre os instintos, emoções e afetos que tem início já nas formas simples de trabalho, para constatarmos que esse é um valor para o qual ocorre exatamente essa dissociação.

Por outro lado, adverte Lukács, o vir a ser consciente dos valores, considerando o ser social como uma totalidade, não é fortuito. A elucidação desse vir a ser consciente exige que se considere que valor é uma relação social em que se mobilizam o indivíduo, o fim e o meio e, por isso, valor possui um "caráter de ser, ontologicamente social" (LUKÁCS, 2013, p. 123). Para Lukács, o ser social do valor também abrange um componente de possibilidade pois em si só pode determinar o âmbito no qual as alternativas efetivas podem ocorrer, assim como pode determinar o cerne social e individual dessas alternativas e as direções em que se pode solucionar os problemas presentes nas alternativas. Lukács enfatiza que "valor, através dos atos que o realizam, alcança o desdobramento desse ser em si [do valor], sua elevação para o verdadeiro serpara-si” (Idem). A práxis humana está inexoravelmente entrelaçada com o valor, sendo o valor o que compele sua efetivação a suas determinações, sem que isso signifique que possamos deduzir intelectualmente do valor a sua realização. Alternativas são alicerces incontornáveis da práxis humano-social e só podem ser desagregadas abstrativamente, pelo intelecto, e não realmente, das decisões individuais. Para o ser social, o sentido da decisão dentre alternativas submete-se ao valor, ou ainda, depende "do complexo respectivo das possibilidades reais de reagir praticamente ante a problematicidade de um hic et nunc histórico-social" (Idem). Consequentemente, decisões frente a alternativas que efetivam possibilidades autênticas, homologando ou não o valor, constituem-se, em cada fase do desenvolvimento do ser social, em modelo exemplar positivo ou negativo.

A exemplaridade, nas formações sociais ainda pouco mediadas, nos diz Lukács, é transmitida oralmente e os heróis da mitologia dessas formações são aqueles indivíduos que ao se posicionaram frente às alternativas, que surgem na vida dessas comunidades, oferecem respostas que devenham relevantes socialmente e permanentemente (seja de modo positivo ou negativo) para a reprodução da comunidade 
em seu processo de mudança e preservação que tipifica a substância do ser social. Lukács acrescenta que a permanência da exemplaridade é insuficiente para explicar o que é a marcha de formação de valores universais. Na verdade, nos diz o autor húngaro, é preciso notar que a exemplaridade dos valores universais exige, para além da permanência, a capacidade de sofrer, de modo incessante, modificações na forma como o exemplo é interpretado em cada cotidiano contemporâneo vivido pelo gênero humano ou, para dizer de outro modo, modificações permanentes na sua serventia "como modelo para a práxis do respectivo presente" (LUKÁCS, 2013, p. 124). O destaque é que se tratam de ações voltadas para uma alternativa social e, por consequência, o momento decisivo da mudança da forma de interpretação do valor é assentado nas necessidades sociais manifestas em cada presente de cada comunidade - são essas necessidades que irão indicar "se e como a alternativa assim fixada deve ser interpretada" (Idem). Como conclusão provisória, Lukács nos diz que mudança e permanência são produtos do desenvolvimento do ser social e sua correlação é a manifestação da substancialidade do ser social (permanência na mudança que se modifica) sendo o valor, em sua objetividade historicamente determinada, ingrediente orgânico de tal substancialidade. $\mathrm{O}$ valores que se conservam ao longo da história do gênero humano sempre se referem (de modo consciente ou não, de maneira imediata ou com amplas mediações) ao desenvolvimento econômico. Dentre os instantes desse processo histórico-social, aqueles que são tocados e atingidos pela alternativa acarretam importantes diferenças factuais, consequentemente esse é o caminho que possibilita aos valores permanecerem, renovando-se continuamente, na totalidade do processo social - por essa via, os valores devêm partes efetivas constitutivas do ser social em seu inexorável processo de reprodução.

\section{Considerações Finais - Liberdade e Humanização do Ser Humano}

A constituição ontológica do trabalho universal/geral - fundante do ser social - é o início da gênese lógica da categoria liberdade. Não poderemos apresentar de modo adequado e exaustivo, por limitação de espaço, a estrutura originária que possibilita a gênese da liberdade e as formas subsequentes dela decorrentes e as diferenças qualitativas que surgem e modificam a estrutura originária da própria liberdade. De imediato destacamos, com Lukács (2013, p. 137), que a liberdade é uma questão de difícil trato pois se constitui de manifestação fenomênica do desenvolvimento do ser social que assume diversos aspectos, muitos lados e passa por alterações e mudanças. Cada espaço 
particular do ser social, quando devém parcialmente autônomo, desenvolve sua própria legalidade, produz sua própria forma de liberdade e o desenvolvimento social e histórico desse espaço gera modificações importantes nessa liberdade. Por isso Lukács (Idem) nos lembra que liberdade no sentido jurídico é consideravelmente distinta da liberdade em sentido político, ético-moral etc.

Elucidar a gênese da liberdade a partir do trabalho universal/geral exige observar que os pores teleológicos necessariamente constituem alternativas e é nas alternativas que surge em primeiro lugar a liberdade da escolha - com destaque para o fato de que a natureza, tanto orgânica quanto inorgânica, desconhece esse conceito. Como primeira aproximação, Lukács (2013, p. 138) nos diz que liberdade é ato de consciência que ao ser posto origina um novo ser: o ser social. Tomando a liberdade como circunstância da realidade, evidencia-se que o sustentáculo da liberdade, segundo o autor, encontra-se nas decisões reais que são tomadas frente a possibilidades concretas. Liberdade, prossegue o autor, é um desejo de modificar (ou conservar) o real existente, o que ratifica que a realidade enquanto matéria a ser transformada tem que estar presente ao considerarmos a liberdade. Já vimos que o pôr teleológico secundário opera e tem papel central para a explicação das formas mais mediadas do ser social, todavia, as consciências só se relacionam de modo real com o problema da liberdade a partir da explicitação da intenção de transformar a realidade.

Uma questão difícil, segundo Lukács (2013, p. 138), é até que ponto se pode ter na determinabilidade interna ou externa da tomada de posição o critério da liberdade (dessa tomada de posição). Para o autor, liberdade é algo próprio ao gênero humano e sempre se apresenta sob certas determinações, condições, ou seja, sempre é condicionada. O ser humano age sob certas condições (objetivas e subjetivas) e seu agir aciona consequências que lhe escapam ao controle e impõe, retroativamente, outros tantos limites à liberdade de decidir e agir. O agir humano, e o trabalho enquanto protoforma do agir, conforme vimos anteriormente, já o demonstra, envolve o conhecimento dos nexos causais e das legalidades dadas e, desse modo, quanto maior esse conhecimento, maiores as possibilidades da reorganização das cadeias causais dadas em cadeias causais postas pelo pôr do fim. Nesse quadro, a ampliação do conhecimento da espécie humana significa maior domínio humano sobre as cadeias dadas e a liberdade de agir sobre a matéria. Lukács (2013, p. 140) prossegue e sustenta que a tomada de decisão frente a alternativas 
é o eixo de um complexo social que, entre seus elementos dinâmicos, insere determinabilidade e liberdade.

O pôr teleológico, que constitui o novo que é o ser social, é uma ação da liberdade surgente, posto que, defende nosso autor, as vias para o atendimento das necessidades já não são consequência de cadeias causais naturais inconscientes; ao contrário, agora se trata do agir consciente do ser humano - sem esquecer que aqui necessidade possui o autêntico caráter do "se...então". Não escapa a Lukács que esse mesmo ato, que é de liberdade, é justamente determinado pela necessidade (que por sua vez é conformada pela sociabilidade que instaura o tipo de necessidade, sua qualidade etc.); verifica-se aqui a simultaneidade e interrelação de determinabilidade e liberdade. Conforme vimos anteriormente, todo agir no processo de trabalho é estruturado por cadeias de alternativas. O ser humano que trabalha é, em seu ser-em- si, resultado das relações sociais que preexistem a ele e, ao mesmo tempo, seu trabalho modifica e reconfigura o seu ser-em-si. Aqui se explicita que o vir-a-ser do produtor tem por fundamento um terreno que por um lado é social e por outro natural e que já comparecem desde os primórdios do trabalho universal/geral enquanto potencialidades (dynamis) de agir do produtor. Em suma, a liberdade na qualidade de alternativa tem uma essência ontológica concreta e não abstrata e universal. No dizer de Lukács, a liberdade "representa determinado campo de força das decisões no interior de um complexo social concreto no qual operam simultaneamente, objetividades e forças tanto naturais como sociais" (LUKÁCS, 2013, p. 141).

Ao considerar a sociabilidade mais mediada e, portanto, o predomínio dos pores teleológicos de segunda ordem, precisamos observar em que se modifica o conceito de liberdade que, até o momento, vínhamos analisando a partir do trabalho simples e de suas consequências. Se no trabalho simples a subjetividade do produtor cumpre papel de pouco destaque, a situação se modifica agora; aqui a liberdade tem por arrimo as decisões entre alternativas que surgem nas circunstâncias parciais e no processo total da sociedade. Nesse caso já não é possível deduzir a liberdade imediatamente do trabalho universal/geral e, tampouco, buscar sua origem no livre movimento da matéria; ainda assim, algumas de suas determinações essenciais permanecem mesmo que com importância distinta nos vários âmbitos da práxis humana. Como exemplos, Lukács (2013, p. 152) nos diz que: (a) o pôr do fim, associado a alternativas, permanece ativo em toda práxis ainda que ocorram transformações, aperfeiçoamentos e internalizações; (b) a

\begin{tabular}{|l|l|l|l|l|}
\hline Q & Ano 10 & n. 23 & Maio - Agosto 2021 & p. 365 - 394 \\
\hline
\end{tabular}


associação intrínseca e inseparável entre determinabilidade e liberdade, que tipifica o pôr do fim, também permanece.

Lukács (Idem) assinala que a principal mudança, ao se analisar a sociabilidade dominada pelos pores teleológicos secundários, é verificada na relação entre meio e fim. A tensão que existe entre meio e fim, e que já se apresenta no trabalho simples produtor de valores de uso, se desenvolve em intensidade e extensão quando consideramos que o objetivo do pôr do fim não é a modificação da natureza (orgânica e inorgânica), mas a modificação de outros seres humanos. A concomitância entre determinabilidade (da realidade social) e liberdade (das tomadas de decisão) permanece; todavia, há uma evidente alteração na qualidade da alternativa. No caso do trabalho simples trata-se do certo ou errado verificável de modo cognitivo; no caso do pôr secundário o pôr teleológico é produto de "alternativas cuja origem é humano-social" (LUKÁCS, 2013, p. 152). Nosso autor arremata esse ponto dizendo que nas sociabilidades mais mediadas, em que se verifica a presença de possuidores e não possuidores ${ }^{14}$, quaisquer disputas serão resolvidas de acordo com os interesses materiais desses grupos. Por fim, considerando essas observações, ressalta que o pôr teleológico, em sociabilidades mais mediadas, já não pode ser mensurado pelos critérios do trabalho simples. Nessas sociabilidades é o seu próprio caráter social - as decisões alternativas dos seres humanos - o que constitui o material das causalidades postas e estas causalidades postas se efetivam nos meios para a obtenção do fim ideado; um material que, ao contrário do que ocorre com o trabalho simples, não é homogêneo e está em permanente devir.

Nesse ponto é incontornável tratar da importância crescente que adquirem as decisões subjetivas nas alternativas. Lukács (2013, p. 154) pondera que esse é um fenômeno social no qual não se verifica a relativização subjetivista da objetividade social; ao contrário, o próprio devir objetivo do ser social constitui funções que só podem vir-aser mediante o peso crescente das decisões subjetivas. O ressalto é dado para o fato de que nessas decisões subjetivas há um conjunto de valorações que são (pelas decisões subjetivas) legitimadas e que se encontram (o conjunto de valorações) estribados na qualidade social objetiva dos valores, na significância desses valores para 0 desdobramento real do gênero humano. Prosseguindo sobre as valorações, Lukács (2013,

14 Na verdade, Lukács fala em classes sociais e interesses de classe. Todavia, advogamos que a categoria classe social só efetiva sua potencialidade na sociedade do capital. Ver nota de rodapé anterior.

\begin{tabular}{|l|l|l|l|l|}
\hline Q & Ano 10 & n. 23 & Maio - Agosto 2021 & p. 365 - 394 \\
\hline
\end{tabular}


p. 154) adverte que sua validade ou não validade e a força, o vigor e o espaço de tempo em que sua ação se manifesta são produtos da objetividade do processo social.

Já dissemos, seguindo Lukács e Marx, que o trabalho executado pelo produtor retroage sobre ele já na forma mais simples do trabalho criador de valores de uso. Naturalmente, algo semelhante se verifica nas práxis que têm por objetivo a consciência de outros humanos (e que têm no trabalho sua protoforma), ainda que ocorram alterações reais quanto aos modos como essa retroação opera. Há, nesse caso, o acento na obrigatoriedade do autodomínio do produtor, no controle e comando permanente de seus instintos, afetos, emoções etc. e, como já sabemos, este é o caminho para o devenir humano do ser humano - a luta permanente do humano contra a fundação humana naturalmente oferecida e o desenvolvimento e aperfeiçoamento do que especifica a condição puramente social, portanto, particular do humano. O produtor nesse processo, mesmo sem ter consciência, se autoproduz como parte constitutiva e constituinte do gênero humano. Para o autor magiar, essa rota para o autocontrole humano - que partindo da determinabilidade natural das emoções, instintos e afetos pode chegar ao autodomínio consciente deste conjunto - é a via efetiva exclusiva que conduz à verdadeira e autêntica liberdade humana. Pois o autodomínio do ser humano, o domínio sobre a sua essência que, originalmente é somente orgânica, é uma ação de liberdade, um sustentáculo da liberdade para a vida do ser humano (LUKÁCS, 2013, p. 156). Lukács prossegue e acrescenta que nesse ponto a questão da genericidade no ser do ser humano e a questão da liberdade se encontram. Como já explanamos, o pôr de finalidades que caracteriza o trabalho especificamente humano aciona a superação da mudez orgânica (biológica) do gênero (humano) e o instaura enquanto gênero estruturado e que se autodesenvolve, do ser humano que se estabelece como singularidade da universalidade que é o gênero humano ou o ser social e, nessa mesma ação há o nascimento da liberdade. Essa liberdade constituída já pelo trabalho primordial produtor de valores de uso era, com razão, rudimentar e restrita; não obstante, a liberdade mais elevada, destilada e sublime - que só pode surgir com o ser social mais complexo e mediado - tem que ser alcançada através de procedimentos análogos com os quais se obteve aquela liberdade ainda rudimentar associada ao trabalho simples. O produto da liberdade mais elevada, pouco importando a consciência de cada singularidade humana envolvida no processo, possui, no final das contas, o mesmo teor que o observado na liberdade rudimentar associada ao trabalho simples e que, resumidamente, pode ser enunciado como: “o domínio do indivíduo

\begin{tabular}{|l|l|l|l|l|}
\hline Q & Ano 10 & n. 23 & Maio - Agosto 2021 & p. 365 - 394 \\
\hline
\end{tabular}


genérico sobre a sua própria singularidade particular, puramente natural" (Lukács, 2013, p. 156). Com Lukács encerramos afirmando que por esses motivos é possível sustentar que o trabalho é o modelo de toda liberdade.

\section{Referências}

ARAUJO, P. H. F.. Dominação Abstrata. Capital: Sujeito Histórico. GERMINAL: Marxismo e Educação em Debate, v. 12, p. 348-362, 2020a.

ARAUJO, P. H. F. As categorias classes sociais e Estado no Livro Primeiro de O capital. Revista da Sociedade Brasileira de Economia Política, v. 56, p. 21-47, 2020 b.

ARAUJO, P. H. F. Notas Críticas à compreensão de Lênin sobre o Estado: revisitando $\boldsymbol{O}$ Estado e a Revolução. Revista da Sociedade Brasileira de Economia Política, v. 50, p. 114-141, 2018.

ARAUJO, P. H. F. Marx: Capital, Estado e política: notas. Revista da Sociedade Brasileira de Economia Política, v. 43, p. 37-62, 2016.

CHASIN, J. Marx: Estatuto Ontológico e Resolução Metodológica, São Paulo: Boitempo, 2009, 253p.

DUAYER, M.; ARAUJO, P. H. F. Trabalho Abstrato, Objetivação, Alienação,

Fetiche - Marx lido por Postone. In: Anais do XXV Encontro Nacional de Economia Política, Salvador, 2020a.

DUAYER, M.; ARAUJO, P. H. F. Valor como Forma de Mediação Social: Interpretação de Marx a partir de Postone. Revista da Sociedade Brasileira de Economia Política, v. 57, p. 45-82, 2020 b.

DUAYER, M.; ARAUJO, P. H. F. Para a crítica da centralidade do trabalho: contribuições de Lukács e Postone. Revista Em Pauta, v. 13, p. 15-36, 2015.

LUKÁCS, G. Para uma ontologia do ser social I, São Paulo: Boitempo, 2012, 436p.

LUKÁCS, G. Para uma ontologia do ser social II, São Paulo: Boitempo, 2013, 845p.

LUKÁCS, G. História e Consciência de Classe - Estudos sobre a dialética marxista, São Paulo: Martins Fontes, 2003. 598p.

MARX, K. H. O capital: crítica da economia política: livro 1: o processo de produção do capital. São Paulo: Boitempo, 2017. 894p.

MARX, K. H. Grundrisse: manuscritos econômicos de 1857-1858: esboços da crítica da economia política. São Paulo: Boitempo, 2011b. 788p. 
Paulo Henrique Furtado de Araujo

POSTONE, Moishe. Tempo, trabalho e dominação social: uma reinterpretação da teoria crítica de Marx. São Paulo: Boitempo, 2014. 483p. 